\title{
An Analysis of Factors which Contribute to Admission of Patients to Medical Wards ${ }^{*}$
}

\author{
Capt M J O'B Minogue \\ MB, DRCOG, RAMC \\ 1st Bn Queen's Regt., Canterbury
}

\section{Introduction}

It has long been felt that there is sometimes more to the reasons why patients are sent or come to hospital than the bald diagnosis which appear on the discharge summary. This analysis is an attempt to look into factors which might have influenced admission other than the obvious physical illness for which investigation and treatment was sought.

All patients admitted to Medical Ward BMH Rinteln under the care of the physicians from 16th March to 17 th July 1981 were studied. The analysis did not include patients admitted under the care of the psychiatrist.

\section{Methods}

A letter was sent to all general practitioners in the Rinteln catchment area two weeks before the analysis began. This encouraged them to write on the referral notes any factors which they felt might have influenced admission. In addition, specific questions were asked of all patients admitted to Medical Ward in this period to try to determine whether any of six factors might have aggravated or caused their illness. From this information the numbers of contributory or causative factors were estimated. Each patient could have more than one main factor or more than one contributory factor allotted in the analysis.

\section{Factors analysed}

1. Service turbulence: For example, husband away, recent posting in, impending posting out, frequent postings, frequent exercise or unaccompanied tours.

2. Alcohol or drug abuse: Into this category come the overdoses (parasuicides and suicides) as well as alcohol intoxication. All those patients who were admitted for endoscopy whose drinking habits were considered to be contributory to their illness were allotted to this category.

3. Housing factors: Into this category came those patients who felt that their quarter was so unsatisfactory that it was contributing to their illness.

4. Marital disharmony.

5. Domestic problems: For example, family illness \& or crisis, financial problems, husband in trouble at work.

6. Sexual problems.

\section{Results}

The total number of patients admitted was 332 . Males $183(55 \%)$, Females $149(45 \%)$.

1. Service Turbulence: In 60 patients $(18 \%)$ it was felt that this was a contributory factor in their ife ness. In 10 patients (3\%) it was felt that this was main factor. For example:

(a) Five patients cited this factor as a ma reason for parasuicide.

(b) One patient with myasthenia gravis was semf on exercise and relapsed.

(c) One visitor was admitted who became ill as result of making the journey to see his famil recently posted.

2. Alcohol/Drug: In 59 patients $(18 \%)$ it was fe that this was a contributory factor in their illness. The major proportion of this group were provided by those admitted for endoscopy (45 out of 52 admitted for endoscopy).

In 42 patients $(13 \%)$ it was felt that this was the main cause for admission. The parasuicides comprised 31 of these patients.

3. Housing Factors: In 20 patients $(6 \%)$ it was felt that this was a contributory cause to their admission.

In one patient $(0.3 \%)$ it was felt that this was the main cause. In fact she suffered severe headaches which were most frequently triggered by noise from the dwellings around the flat, from within the flat (central heating) and from outside her flat (an adjacent motorway and railway line).

4. Marital Disharmony: In 28 patients $(8 \%)$ it was felt that this was a contributory cause to their admission. This contributed to parasuicide in some, to abdominal pain, palpitations, chest pains and other physical symptoms which could be related to anxiety or depression in others.

In four patients $(1 \%)$ this was the main cause of parasuicide. 
5. Domestic Problems: In 34 patients $(10 \%)$ it was felt that this was a contributory cause to their admission. A similar spectrum of symptoms were produced as those found under 4 above.

6. Sex Problems: In 23 patients ( $7 \%$ ) it was felt that this was a contributory cause to their admission. This category overlapped with marital disharmony in all cases.

However, in one patient $(0.3 \%)$ this was the main reason for parasuicide.

It was felt that the figures in this category were probably falsely low as the duration of admission of parasuicides is usualy too short to evaluate fully sexual problems.

\section{Additional Statistics}

(a) Parasuicides-31: Seventeen males, nine single -.eight married and 14 females-all married.

(b) Endoscopies-52: Thirty three males and 19 females.

(c) Staff Members-9.

(d) Visitors to BAOR (dependants)--9: Two died.

(e) Deaths-3.

\section{Comments}

The problem about the analysis was that it was of necessity based on personal opinions of the contribution of the factors to the illness. However the same general rules were applied throughout and tended to err on the side of not entering factors into the statistics if these were in any doubt (see comment under sex problems).

It was perhaps surprising that there were more male parasuicides than female and of note that more than half of the men were unmarried. A previous survey in this hospital has shown that in 1976-1977 parasuicide was nearly twice as common in females than males ${ }^{1}$. As was the case in that survey, this survey recorded no fatalities from drug overdose. Past surveys in England indicated that depression is twice as common in females in the age group covered by this project ${ }^{2}$.

Housing problems were not seen to be a major contributory factor to illness.

On the other hand service turbulence was a significant factor in contributing to illness on the medical ward. Many of these problems revolved around the correct medical grading of patients, which of course is less important in civilian practice. Either people were sent to places where their grade did not allow them to go or their admission was for assessment of grade and, thus of where they could go and what they could do.

Some patients were admitted with minor illness from exercise or from the hospital staff simply because there was no suitable place where they could otherwise be bedded down. These appear as service turbulence statistics rather than under housing.

Alcohol and drug ingestion was implicated as a main or contributory cause for admission in nearly one in three patients on the ward.

Of the total 332 patients, it was felt that 194 patients had none of these factors contributing to their illness.

\section{Conclusion}

The factors studied did indeed have a significant influence on admissions to medical ward with service turbulence, alcohol and drug abuse being the most important factors.

It is likely that little can be done to reduce service turbulence although it should be considered as an added stress when assessing fitness to serve.

General Practitioners may see alcohol and drug abuse as an area worthy of study with respect to reducing numbers of admissions to medical wards. Studies of barbiturate self poisoning, for example, have shown that the incidence of self poisoning with these substances is an accurate reflection of their prescription rate $^{3}$.

\section{Acknowledgements}

I wish to acknowledge with grateful thanks the advice and help given me by Colonel J D Cormack L/RAMC during the writing of this paper. I would also like to thank the General Practitioners of the Rinteln area who responded to my letter.

\section{REFERENCES}

1 JonNSTON, J $\mathrm{H}$ et al. Self-poisoning in a military community. I R Army Med Corps 1980; 126: 88-91.

2 FrY, JoHN. Common Disease, their nature incidence and care. 2nd Ed: 314.

3 JoHNS, M W. Self poisoning with barbiturates in England and Wales during 1959-1974. Br Med J 1977; 1: 1128-1130. 